\title{
Role of Trapezius Transfer for Shoulder Reconstruction in Adult Traumatic Brachial Plexus Injuries: Literature Review
}

\author{
Mahmoud Salama, MD*; Usama Farghaly Omar, MD² \\ 'Department of Orthopedics, Aswan University, Aswan, Egypt \\ ${ }^{2}$ Department of Orthopedics, Al-Hekma Specialized Hospital, Assiut, Egypt
}

\begin{abstract}
Introduction: Shoulder instability and lack of shoulder mobility are common and exhausting problems in adult patients with traumatic brachial plexus injury. Although primary nerve reconstruction remains the "gold standard" for brachial plexus management, secondary shoulder reconstruction by trapezius transfer is needed in neglected cases.

Results: Different upper trapezius transfer techniques are described in detail, starting from the first report by Hoffa et al. up to Rühmann's modification of Saha's technique. Additionally, lower trapezius transfer by Elhassan's technique is discussed to review differences in functional outcome gained by each technique.

Conclusion: Secondary shoulder reconstruction options still have their indications in cases of late presentation and failed nerve surgery. There is a wide spectrum of outcomes due to the variability of the extent of injury. Using the upper and lower trapezius for the possible restoration of abduction and external rotation as described by Elhassan et al. yielded a mean post-operative shoulder abduction and external rotation of approximately $50^{\circ}$ and $20^{\circ}$, respectively. Rühmann's modification of Saha's technique (suturing the partially freed deltoid muscle under maximum tension on top of the trapezius as far medially as possible) showed improvement in the outcomes of stability and abduction recovery ( $34^{\circ}$ mean post-operative shoulder abduction).
\end{abstract}

\section{Introduction}

Shoulder instability and lack of shoulder mobility are common and exhausting problems in adult patients with traumatic brachial plexus injuries. Even with functioning elbow, wrist, and fingers, upper limb function is significantly hampered by deficient shoulder function. Primary nerve reconstruction remains the "gold standard" in brachial plexus management. If surgery is early and successful, adequate reinnervation of the deltoid, teres minor, supraspinatus and infraspinatus muscles can be achieved, as well as glenohumeral joint stability $[1,2]$.

However, secondary shoulder reconstruction is needed in clinical scenarios, such as neglected cases $(>1$ year without any attempt for reconstruction) and cases of complete or partial failure of recovery of both the deltoid and rotator cuff after primary reconstruction.

Many options are available for secondary shoulder reconstruction. Trapezius transfer is one of those important options, and our goal is to review the indications, techniques, and outcomes of trapezius transfer and compare it with the alternative options. First, we should revisit the basic concepts of shoulder kinematics and tendon transfer.

\section{Kinematics of the Shoulder}

The shoulder range of motion is achieved by the scapulohumeral rhythm, which is the coordinated motion of the glenohumeral, scapulothoracic, acromioclavicular and sternoclavicular joints. For shoulder abduction, an approximately 2:1 ratio of glenohumeral to scapulothoracic motion is required [3-5].

The rotator cuff muscles are primarily dynamic stabilizers for the shoulder during abduction, forward flexion, and extension that act by resisting the relative upward shearing moment at the glenohumeral joint by the deltoid in early abduction and through a force couple of the subscapularis anteriorly and the infraspinatus posteriorly [6].

The importance of the force couple function generated by the glenohumeral stabilizers is indicated by the pseudoparalysis of the shoulder in massive rotator cuff tear. This pseudoparalysis extends below the humeral head equator despite normal brachial plexus and deltoid function; however, due to the force couple loss, the humeral head cannot be contained. An important study done by Gerber et al. demonstrated $45 \%$ loss of abduction strength and $70 \%$ loss of external rotation strength after nerve blocks of the infraspinatus. Paralysis of both the supraspinatus and infraspinatus led to a decrease in abduction strength of $75 \%$ and a decrease in external rotation strength of $80 \%$. The teres minor plays a role in external rotation strength at any angle of shoulder abduction less than $20 \%$ [7].

These relations explain why isolated trapezius transfer alone leads to an obligatory proximal migration of the humeral head, narrowing the space between the humeral head and acromion, which causes mechanical impingement and decreases the trapezius lever arm, leading to ineffective shoulder abduction and flexion [8].

The deltoid and rotator cuff muscles have relatively low excursion but generate high tension. The upper trapezius has lower tension but superior excursion. The latissimus dorsi muscle, commonly transferred for shoulder external rotation and abduction, has low strength but high excursion [6]. The basic principles of tendon transfer are difficult to apply to the complex polyaxial shoulder motion, but they should be considered in performing shoulder tendon transfer [8].

\section{Primary Nerve Reconstruction}

Nerve reconstruction options include neurolysis, direct coaptation, nerve grafting to the available healthy nerve roots and nerve transfer. A systematic review by Rohit Garg et al. demonstrated that in upper trunk palsy, shoulder function results after nerve transfers are better than those after nerve grafting, with decreased operative time and morbidity due to exploration and avoidance of both a second incision and the morbidity of harvesting a nerve graft. Therefore, the classic exploration and testing for available donor nerve roots to use with nerve grafting in isolated upper trunk injuries becomes questionable, while for C5-C6-C7 injuries, plexus exploration for potential nerve root donors may be needed [9]. 
Nerve transfers for shoulder reconstruction reviewed by Merrell et al. in a meta-analysis of 1088 cases clearly confirmed that best results for shoulder function were obtained by reinnervation of both the suprascapular and axillary nerves simultaneously, with overall results of $73 \%$ shoulder abduction M3 and 26\% M4. The spinal accessory nerve (98\%) was a significantly better donor nerve than intercostal nerves (56\%) for obtaining M3 shoulder abduction. Regarding the recipient nerve, the suprascapular nerve (92\%) was a significantly better recipient nerve than the axillary (69\%) for obtaining M3 shoulder abduction [10].

Chuang et al. reported good results with a mean shoulder abduction of $55^{\circ}$ in 21 of 21 patients after the simultaneous double nerve transfer of the phrenic to suprascapular nerve and the spinal accessory to axillary nerve [1]. Songcharoen et al. also confirmed that the best results were obtained by the direct transfer of the distal spinal accessory nerve to the suprascapular nerve, with a success rate of $80 \%$ for useful motor recovery of MRC grade 3 or better [11].

The balance between the available donors and the required recipients for nerve transfer in upper trunk palsy increases the ease of neurotizing both the suprascapular and axillary nerves and achieving the best results; however, in more extensive injuries, especially global avulsion palsy, this balance is much more difficult to achieve and a maximum of one nerve transfer for can be done for the shoulder. This situation gives rise to the question of whether the results of secondary reconstruction procedures (fusion or trapezius transfer) are comparable to the results of single nerve transfer for the shoulder; if the answer is yes, the badly needed extraplexal donor nerves can be saved for other recipients or for free functional muscle transfer innervation later on.

\section{Secondary Reconstructive Options}

In patients who fail to develop improved shoulder function after primary nerve reconstruction or in those who present late with no possibility of nerve repair/transfer, secondary reconstructive surgeries, including shoulder fusion or muscle transfer, should be the primary choice.

\section{Shoulder Fusion}

Inferior subluxation reduction of the shoulder and improving chronic shoulder pain, which are the usual complaints in brachial plexus injury patients, are higher priorities than improving range of motion. This logically leads to the shoulder fusion option, which will achieve stability and improve pain; however, this procedure makes shoulder motion completely dependent on scapulothoracic motion, which is deficient in many patients with brachial plexus injuries [12,13].

The disadvantages of losing passive motion of the shoulder, including hindered self-hygiene, should be considered. The irreversibility of the fusion option is also a significant downside compared with the muscle transfer option, and frequent complications were reported by Cofield and Briggs, who noted that the disadvantages of arthrodesis include a high incidence of fracture, worsening of pain and relative reduction of passive movements (35\% complication rate of persistent pain, pseudarthrosis, and incorrect positioning) [14]. Aziz et al. also argued that simple trapezius transfer is compatible with the later return of some function to other shoulder girdle muscles, while arthrodesis is irreversible and no benefits can be derived from any late return of brachial plexus function [15]. Therefore, some authors, such as Goldner and Saha, have discouraged the fusion option except as a last resort if no donor muscles are available [16].

Additionally, fusion may have more advantages over muscle transfer in patients with physically demanding work, who still have a good function in the elbow and hand and those with a post-traumatically impaired shoulder articular surface and a passive abduction range less than $80^{\circ}$ [17].

Nevertheless, recent technical modifications of shoulder fusion have shown better outcomes and changed the bad reputation due to the high complication and nonunion rates. One of the important modifications is to osteotomize the acromion and prepare the acromiohumeral surface for fusion in addition to the glenohumeral surface, which increases the fusion surface area and provides better contouring for plate bending. Another modification is the use of double plating for fixation as shown in Figure 1 [18].

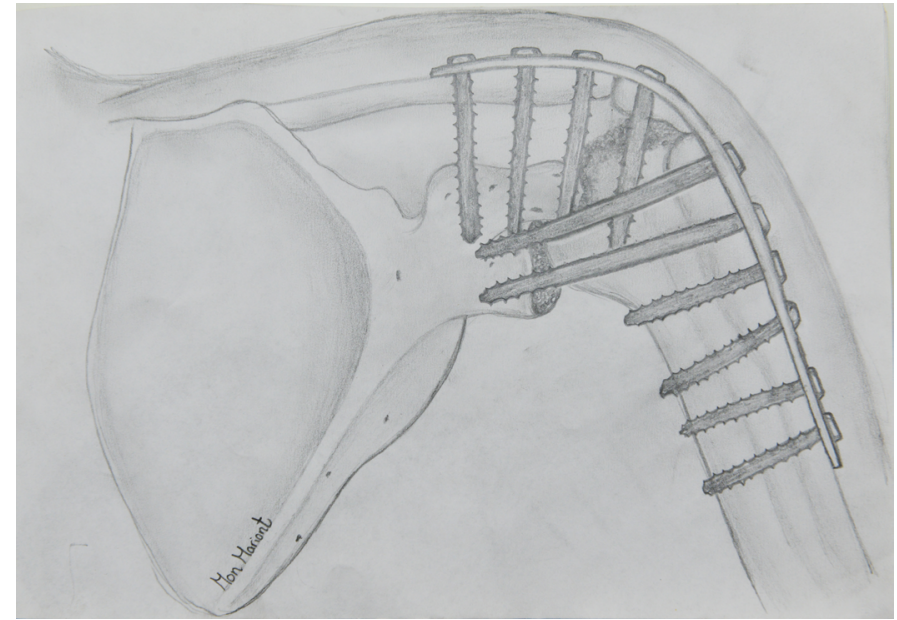

Figure 1. Double plating technique for shoulder fusion.

\section{Muscle Transfers}

In selecting the donor muscle for transfer, it is essential to know the available muscles, their expendability, strength, excursion, and proper vector to permit function. The difficulty comes from the relatively few functional muscles that are available for donation; their expendability is unclear. Additionally, the accurate determination of strength is difficult because of the complex interaction of forces in the shoulder girdle. However, in plexus injuries, the trapezius, levator scapulae, and rhomboids have been reported to be present or to recover in 96\% of patients [19].

The trapezius muscle is spared because of its innervation by the spinal accessory nerve in addition to contributions from C3 and C4. However, it is also usually hypertrophied with deltoid paralysis [20], which is why trapezius transfer is the most commonly reported tendon transfer for shoulder reconstruction in adult brachial palsy [21]. Transfer of the latissimus dorsi and/or teres major may be useful in upper trunk injury, as they are paralyzed in global or complete palsy, which are the most common in adults. Other transfers that should be considered include the levator scapulae, pectoralis major, long heads of the biceps and triceps, and pedicled latissimus flaps.

Multidirectional shoulder instability and insufficient abduction/forward flexion are the indications for trapezius transfer; however, instability remains the main indication and takes more priority than the deficient abduction. Before deciding on a trapezius transfer, exploration of the plexus, neurolysis, repair, nerve transfer or nerve grafting must have been conducted and no improvement obtained after intensive conservative therapy. Paralysis of the deltoid muscle must be complete. The trapezius muscle must show full strength against resistance. To carry out the transfer it is essential that the preoperative passive shoulder abduction is at least $80^{\circ}$ [22].

\section{Operative Technique Evolution Upper Trapezius Transfer Technique}

Trapezius transfer was first described by Hoffa (1891) and then by Lewis (1910) and Lange (1911). The shortage of the trapezius tendon in reaching the deltoid insertion is addressed by elongation with the fascia lata, which is assumed to be a cause of stretching and scarring, leading to poor results [23].

Then, transfer of the trapezius acromial insertion to the proximal end of the humerus was described by Bateman (1955). However, shortage of the lever arm of the transferred trapezius was still an issue. Thus, Saha (1967) modified the technique to provide a more distal fixation of the transfer just distal to the greater tuberosity after a more proximal release, providing a greater lever arm. Additionally, osteotomizing the acromion allows better fixation to the narrow cylindrical shaft of the humerus. Fixation was provided by two $6.5-\mathrm{mm}$ cancellous screws, with the shoulder positioned in abduction from $80^{\circ}$ to $90^{\circ}$. Since that time, Saha's 
name has been associated with the operation.

Rühmann et al. have several publications on trapezius transfer in adult brachial plexus injury [17,22,23]. Originally, Rühmann used Saha's technique; then, he modified the method by suturing the partially freed deltoid muscle under maximum tension on top of the trapezius as far medially as possible. Therefore, the trapezius power acts on the humerus along the deltoid insertion area. He reported significant improvement in outcomes with his modification.

As such, Rühmann's modification of Saha's technique is the most recently described technique. In this technique, the patient is set in the lateral decubitus, and a Y-shaped incision is made with the paired limbs over the clavicle and the spine of the scapula and the vertical limb over the humeral head. The trapezius, deltoid, acromion, clavicle and spine of the scapula are widely exposed. Then, the deltoid is mobilized from the clavicle, the acromion, and the spine of the scapula. Additionally, the upper trapezius is detached from the spine of the scapula and clavicle. The acromion, including the trapezius insertion, is osteotomized from the spine of the scapula. Then, the deltoid and proximal humerus decortication are split longitudinally. The rotator cuff should be left untouched. At $90^{\circ}$ of shoulder abduction, the acromion should be transferred to the humerus just below the greater tuberosity and fixed with two 6.5-mm cancellous screws.

The point of fixation as described by Rühmann was as distal as possible to increase the lever arm; however, trapezius excursion may be lost with maximum distalization. Additionally, he had assumed that the fixa-

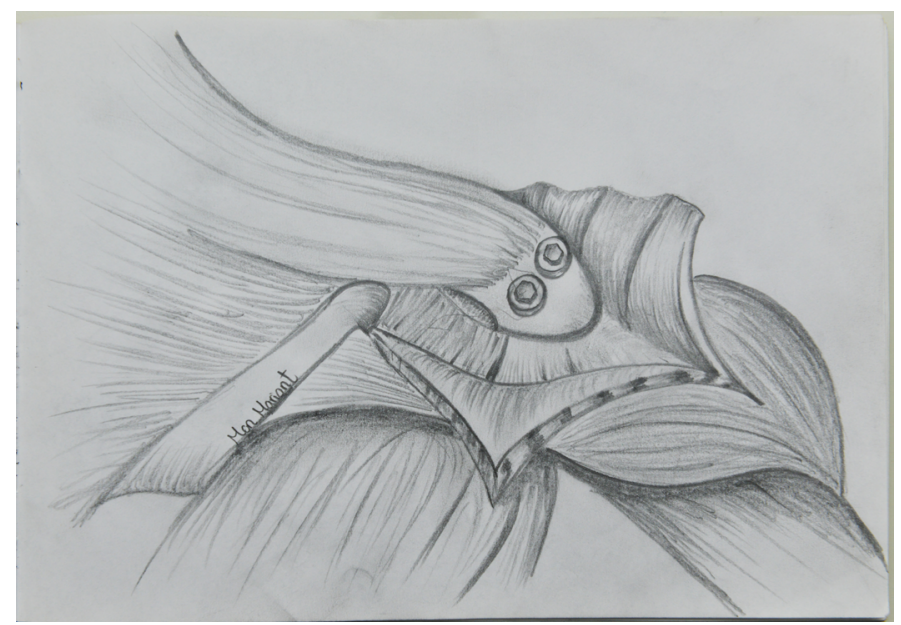

A

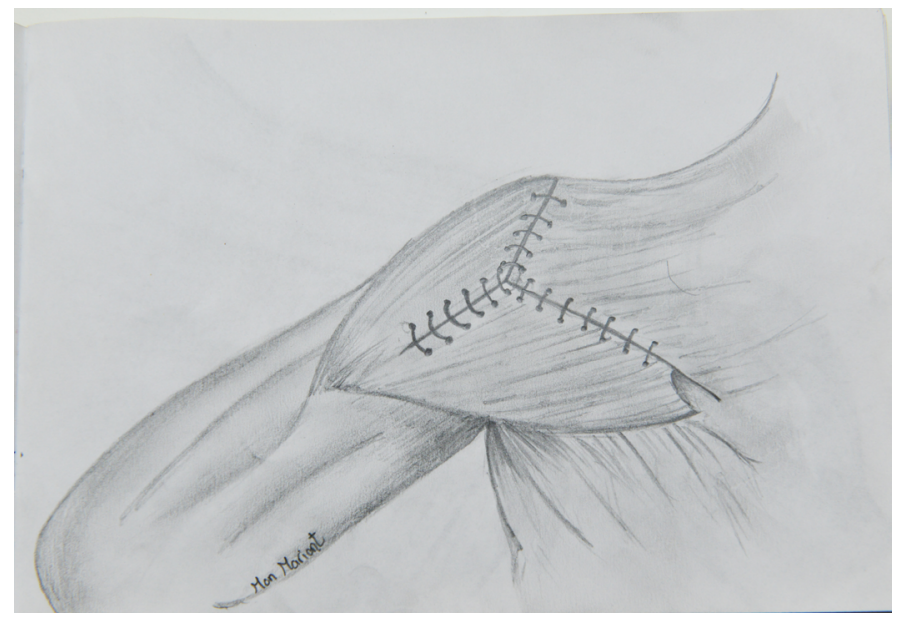

B

Figure 2. (A) Fixation of transferred trapezius with its acromial attachment to proximal humerus. (B) Suturing of deltoid over transferred trapezius. tion point will determine the post-operative function, i.e., anterolateral acromion positioning will lead to an improvement in abduction, forward flexion and internal rotation, and posterolateral acromion positioning will lead to an increase in retroversion and external rotation. Lastly, the deltoid muscle is sutured under maximum tension on top of the trapezius as far medially as possible as in Figure 2.

The post-operative upper limb immobilization for six weeks in a difficult position in terms of abduction and external rotation may be one of the major drawbacks of the procedure.

\section{Lower Trapezius Transfer Technique}

In the original technique described by Elhassan et al. for lower trapezius transfer, prolongation of the lower trapezius with a tendon allograft was used to transfer the lower trapezius to the infraspinatus [24]. Then, he modified his technique with the direct transfer of the lower trapezius tendon to the infraspinatus tendon without using a graft. Two incisions were used; the first being $2 \mathrm{~cm}$ medial to the scapula to harvest the lower trapezius and separate it from the middle trapezius while protecting the spinal accessory nerve, and the second incision being lateral to expose the infraspinatus tendon and peel off the muscle fibers to obtain an approximately $7 \mathrm{~cm}$ length of the tendon, which makes the direct transfer possible without a graft. A deep subcutaneous tunnel between the medial and lateral incision is used to pass the lower trapezius tendon to the infraspinatus tendon as in Figure 3, and tensioning is performed in full external rotation.

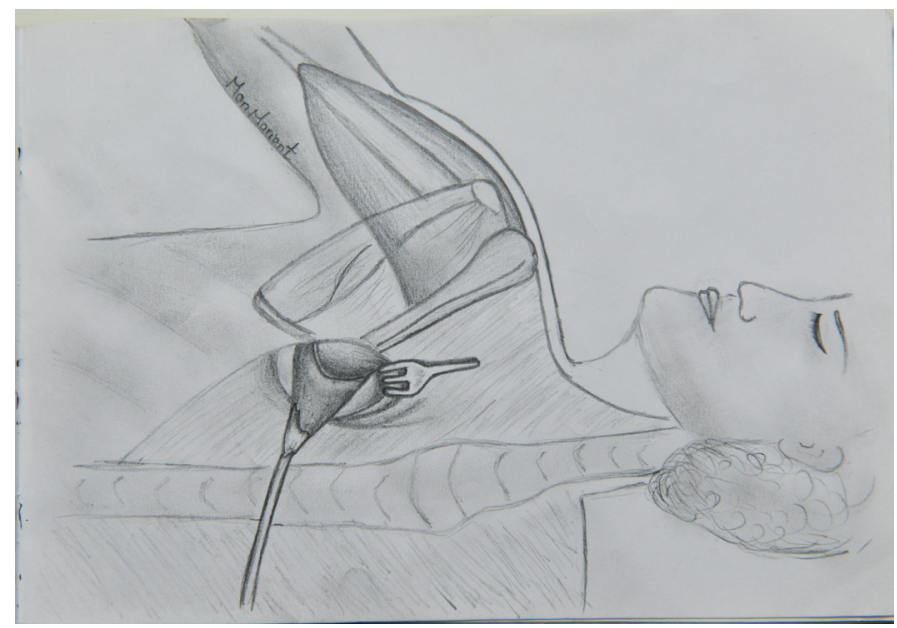

A

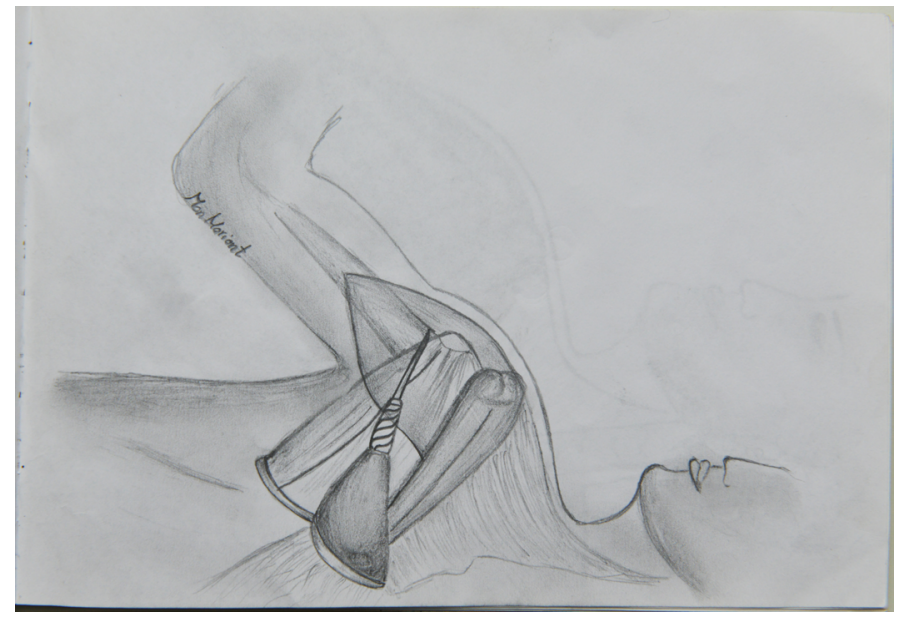

B

Figure 3. (A) Lower trapezius harvesting and passage through subcutaneous tunnel. (B) Suturing lower trapezius tendon in infraspinatus tendon. 
Table 1. Results of Different Trapezius Transfer Techniques

\begin{tabular}{|c|c|c|c|c|c|c|}
\hline Authors & $\begin{array}{l}\text { No. of } \\
\text { Patients }\end{array}$ & Preoperative Status & Operative Technique & $\begin{array}{l}\text { Mean Preoper- } \\
\text { ative Shoulder } \\
\text { Abduction }\end{array}$ & $\begin{array}{l}\text { Mean Post-Op- } \\
\text { erative Shoul- } \\
\text { der Abduction }\end{array}$ & External Rotation \\
\hline $\begin{array}{l}\text { Aziz et al. } \\
{[15] .}\end{array}$ & 27 & $\begin{array}{c}5 \text { cases complete palsy } \\
16 \text { cases } C 5-6 \text { roots } \\
6 \text { cases } C 5-6-7 \text { roots }\end{array}$ & Saha's modification & $4^{\circ}(0$ to 30$)$ & $45^{\circ}$ (20 to 120$)$ & - \\
\hline $\begin{array}{l}\text { Kotwal et al. } \\
{[25]}\end{array}$ & 26 & $\begin{array}{c}8 \text { cases brachial plexus } \\
18 \text { cases post- } \\
\text { poliomyelitis }\end{array}$ & Saha's modification & Not mentioned & $46^{\circ}$ & - \\
\hline $\begin{array}{l}\text { Mir-Bullo et al. } \\
{[26]}\end{array}$ & 6 & $\begin{array}{l}\text { Brachial plexus injury } \\
\text { (not specified) }\end{array}$ & Saha's modification & $13^{\circ}(0-30)$ & $76^{\circ}(50$ to 100$)$ & - \\
\hline $\begin{array}{l}\text { Monreal et al. } \\
{[21]}\end{array}$ & 10 & $\begin{array}{c}6 \text { cases } C 5-6 \\
\text { one case } C 5-6-7 \\
3 \text { cases complete palsy }\end{array}$ & Saha's modification & $3.1^{\circ}\left(0^{\circ}\right.$ to $\left.30^{\circ}\right)$ & 50 & - \\
\hline $\begin{array}{l}\text { Rühmann et al. } \\
\text { [27] }\end{array}$ & 80 & $\begin{array}{l}37 \text { cases complete palsy } \\
43 \text { cases partial BPI }\end{array}$ & $\begin{array}{l}\text { 58: Saha's modification } \\
\text { 22: Rühmann's modification }\end{array}$ & $6^{\circ}(0$ to 45$)$ & $34^{\circ}(5$ to 90$)$ & $\begin{array}{l}\text { Same pre- and } \\
\text { post-operative }\end{array}$ \\
\hline $\begin{array}{l}\text { Bassem } \\
\text { Elhassan et al. } \\
{[28]}\end{array}$ & 52 & $\begin{array}{l}13 \text { cases complete palsy } \\
12 \text { cases } \text { C5-6 roots } \\
22 \text { cases } C 5-6-7 \text { roots } \\
5 \text { cases } C 5-6-7-8 \text { roots }\end{array}$ & $\begin{array}{c}\text { Lower trapezius to } \\
\text { infraspinatus in all cases + } \\
\text { Rühmann's modification in } 39\end{array}$ & $10^{\circ}$ & $50^{\circ}$ & $20^{\circ}$ mean ER gain \\
\hline $\begin{array}{l}\text { Bertelli et al. } \\
{[29]}\end{array}$ & 7 & $\begin{array}{l}3 \text { cases } C 5-6 \text { roots } \\
4 \text { cases } C 5-6-7 \text { roots }\end{array}$ & $\begin{array}{l}\text { Lower trapezius to } \\
\text { infraspinatus + Rühmann's } \\
\text { modification in all cases }\end{array}$ & $0^{\circ}$ & $38^{\circ}$ & $\begin{array}{l}\text { Post-operative } \\
104^{\circ} \text { mean ER } \\
\text { from full IR } \\
\text { position }\end{array}$ \\
\hline
\end{tabular}

\section{Discussion}

Evaluation of reports in the literature of trapezius transfer may be difficult due to the variations in the indications used in each study, and a comparison of the different outcomes may be inappropriate (Table 1). For example, some studies reported optimistic results for post-operative abduction ( $60^{\circ}$ by Kotwal et al., and $76^{\circ}$ by Mir-Bullo et al.), but in the Kotwal study, preoperative abduction range was not reported, and in the Mir-Bullo study, few cases were reported to have a preoperative abduction recovery of $30^{\circ}$. Another important confounder that hampers the unbiased mass analysis of the literature, is the strength of the parascapular muscles, pectoralis major, triceps and biceps. When these muscles are preserved, Rühmann et al. reported an average abduction of $42^{\circ}$ in comparison with $28^{\circ}$ of abduction in completely flail shoulders [23].

A correlation between the biceps status and shoulder stability outcome has been noticed by some authors, which may be due to the long head of the biceps compensating for shoulder instability [22,23,29].

However, scapular winging due to serratus anterior paralysis may be the most important factor of poor results for either trapezius transfer or shoulder fusion, as whatever the range of motion achieved after those surgeries, it is mostly coming from the scapulothoracic motion. Serratus anterior paralysis had been accepted by many authors to be a contraindication for shoulder fusion; however, recently, some authors considered scapular winging a contraindication for trapezius transfer as well [29].

Trapezius transfer has been claimed to provide only a tenodesis effect on the glenohumeral joint and to only provide good functional abduction outcomes via good parascapular and pectoralis major muscles, as well as biceps and triceps [30]. This poor active action on the glenohumeral joint can be explained biomechanically by the humeral head upward migration effect due to reconstructing the deltoid and neglecting the rotator cuff reconstruction, which led to the recent evolution of the combined reconstruction of the deltoid and rotator cuff. Elhasssan et al. emphasized the importance of addressing external rotation and not only abduction in adult brachial plexus injuries. However, as mentioned for adults, unlike in pediatric cases, the donor muscles available for transfer are limited as the latissimus dorsi and teres major are usually paralyzed.

This situation gives rise to the need for using the trapezius to reconstruct two actions, abduction and external rotation, by transferring the upper trapezius to the deltoid and the lower trapezius to the infraspinatus trapezius, a multipennate muscle that according to Herzberg et al., can be divided into the functional subcomponents [6]. Independent control of the upper and lower trapezius muscle has been confirmed by Holterman et al. [31].

Promising results were obtained with the combined abduction and external rotation reconstruction using the upper and lower trapezius by Bertelli et al. in seven cases, with a mean abduction of $39^{\circ}$ and external rotation of $104^{\circ}$ from the full internal rotation position [29]. These results agree with those of a study by Elhassan et al. on fifty-two cases, in which he transferred the lower portion of the trapezius muscle to the infraspinatus in isolation in five patients and as part of multiple tendon transfers, including the upper and middle portions of the trapezius, to the deltoid in thirty-nine patients; outcomes of a mean external rotation gain of $20^{\circ}$ and a mean abduction gain of $40^{\circ}$ were recorded [28].

In most of cases that have been managed previously by primary nerve reconstruction, the spinal accessory nerve is used as a donor nerve. In these cases, the middle and lower trapezius are paralyzed, which precludes use of the lower trapezius for tendon transfer. Nevertheless, upper trapezius tendon transfer is still possible in cases where the spinal accessory nerve was used previously for nerve transfer [16]. However, a comparison of the outcomes of trapezius transfer with or without a previous spinal accessory nerve transfer has not yet appeared in the literature.

Further research is required to determine the expected outcomes of trapezius transfer after prior spinal accessory nerve use for nerve transfer. Are the outcomes comparable to the results of the classic single spinal accessory nerve to suprascapular nerve transfer? If so, a strategy worth considering is saving the spinal accessory nerve to neurotize the elbow flexors or free gracilis for finger flexion in total brachial plexus and depending on trapezius transfer for reconstructing the shoulder. 


\section{Conclusion}

While primary nerve reconstruction is the gold standard management choice in the early presentation of brachial plexus injuries, secondary shoulder reconstruction options (fusion or trapezius transfer) still have their indications in late presenting cases ( $>1$ year after injury) or cases of failed nerve surgery ( $>2$ years after surgery). The wide variability of the extent of injury within that the spectrum of indicated cases for secondary shoulder reconstruction leads to variable outcomes. Outcomes can range from very good results in cases of partial brachial plexus injuries (preserved parascapular and pectoralis major muscles) presenting late in which the spinal accessory nerve was not previously used with the upper and lower trapezius for possible restoration of abduction and external rotation to poor results in cases of total brachial plexus injuries (winging scapula) presenting after failed nerve surgery in which the spinal accessory nerve was used for nerve transfer and the possibility of using the lower trapezius is precluded and no other donor nerves are available for tendon transfer.

As shoulder fusion with the modified techniques of acromion osteotomy and the use of double plating for fixation has achieved better outcomes and fewer complications, the procedure still has its place, especially in patients with the high physical demands, post-traumatically arthritic articular surface, and stiff shoulders.

Rühmann's modification of Saha's technique with acromion osteotomy fixation as distally as possible and tensioning the deltoid closure has achieved improved outcomes in terms of stability and abduction recovery. Promising reports of lower trapezius transfer to the infraspinatus make external rotation recovery (which is functionally significant) possible in these patients. However, this new transfer is not available in many cases off failed nerve surgery, as the spinal accessory nerve has usually been transferred.

\section{Article Information}

*Correspondence: Mahmoud Salama, MD

Department of Orthopedics, Aswan University, Aswan, Egypt.

E-mail: mahmoudsalamaegy1@yahoo.com

Received: Oct. 15, 2017; Accepted: Jan. 29, 2018; Published: Apr. 16, 2018

DOI: $10.24983 /$ scitemed.imj.2018.00058

Copyright $\odot 2018$ The Author(s). This is an open-access article distributed under the terms of the Creative Commons Attribution 4.0 International License (CC-BY).

\section{Funding: None}

\section{Conflict of Interest Disclosures: None}

\section{Acknowledgement:}

Authors would like to thank Mina Mamdouh for his help in drawing the article's figures.

\section{Keywords}

Brachial plexus injury; shoulder function; shoulder fusion; trapezius transfer.

\section{References:}

1. Cardenas-Mejia A, O'Boyle CP, Chen KT, Chuang DC. Evaluation of single-, double-, and triple-nerve transfers for shoulder abduction in 90 patients with supraclavicular brachial plexus injury. Plastic and Reconstructive Surgery 2008;122(5):1470-1478.

2. Terzis JK, Barmpitsioti A. Axillary nerve reconstruction in 176 posttraumatic plexopathy patients. Plastic and Reconstructive Surgery 2010;125(1):233-247.

3. Murray IR, Goudie EB, Petrigliano FA, Robinson CM. Functional anat- omy and biomechanics of shoulder stability in the athlete. Clinics in Sports Medicine 2013;32(4):607-624.

4. Halder AM, Itoi E, An KN. Anatomy and biomechanics of the shoulder. Orthopedic Clinics of North America 2000;31(2):159-176.

5. Terry GC, Chopp TM. Functional Anatomy of the Shoulder. Journal of Athletic Training 2000;35(3):248-255.

6. Herzberg G, Urien JP, Dimnet J. Potential excursion and relative tension of muscles in the shoulder girdle: relevance to tendon transfers. Journal of Shoulder and Elbow Surgery 1999;8(5):430-437.

7. Gerber C, Blumenthal S, Curt A, Werner CML. Effect of selective experimental suprascapular nerve block on abduction and external rotation strength of the shoulder. Journal of Shoulder and Elbow Surgery 2007;16(6):815820.

8. Elhassan B, Bishop A, Shin A, Spinner R. Shoulder tendon transfer options for adult patients with brachial plexus injury. Journal of Hand Surgery 2010;35(7):1211-1219.

9. Garg R, Merrell GA, Hillstrom HJ, Wolfe SW. Comparison of nerve transfers and nerve grafting for traumatic upper plexus palsy: a systematic review and analysis. Journal of Bone and Joint Surgery: American Volume 2011;93:819-829.

10. Merrell GA, Barrie KA, Katz DL, Wolfe SW. Results of nerve transfer techniques for restoration of shoulder and elbow function in the context of a meta-analysis of the English literature. Journal of Hand Surgery 2001;26(2):303-314.

11. Songcharoen P, Wongtrakul S, Spinner RJ. Brachial plexus injuries in the adult. Nerve transfers: the Siriraj Hospital experience. Hand Clinics 2005;21(1):83-89.

12. Hawkins RJ, Neer CS II. A functional analysis of shoulder fusions. Clinical Orthopaedics and Related Research 1987;(223):65-76.

13. Richards RR, Sherman RM, Hudson AR, Waddell JP. Shoulder arthrodesis using a pelvic-reconstruction plate. A report of eleven cases. Journal of Bone and Joint Surgery: American Volume 1988;70(3):416421.

14. Cofield RH, Briggs BT. Glenohumeral arthrodesis. Operative and long-term functional results. Journal of Bone and Joint Surgery: American Volume 1979;61(5):668-677.

15. Aziz W, Singer RM, Wolff TW. Transfer of the trapezius for flail shoulder after brachial plexus injury. Journal of Bone and Joint Surgery. British Volume 1990;72(4):701-704.

16. Saha AK. Surgery of the paralysed and flail shoulder. Acta Orthopaedica Scandinavica 1967; Suppl 97:5-90.

17. Rühmann O, Gossé F, Wirth CJ, Schmolke S. Reconstructive operations for the paralyzed shoulder in brachial plexus palsy: Concept of treatment. Injury 1999;30(9):609-618.

18. Clare DJ, Wirth M, Groh GI, Rockwood CA Jr. Shoulder arthrodesis. Journal of Bone and Joint Surgery: American Volume 2001;83-A(4):593600.

19. Narakas AO. Muscle transpositions in the shoulder and upper arm for sequelae of brachial plexus palsy. Clinical Neurology and Neurosurgery 1993;95 Suppl:S89-91.

20. Comtet JJ, Herzberg G, Naasan IA. Biomechanical basis of transfers for shoulder paralysis. Hand Clinics 1989;5(1):1-14.

21. Monreal R, Paredes L, Diaz H, Leon P. Trapezius transfer to treat flail shoulder after brachial plexus palsy. Journal of Brachial Plexus and Peripheral Nerve Injury 2007;12:2.

22. Ruhmann O, Wirth CJ, Gosse F, Schmolke S. Trapezius transfer after brachial plexus palsy. Indications, difficulties and complications. Journal of Bone and Joint Surgery. British Volume 1998;80(1):109-113.

23. Ruhmann O. Schmolke S, Bohnsack M, Carls J, Wirth CJ. Trapezius transfer in brachial plexus palsy: Correlation Of The Outcome With Muscle Power And Operative Technique. Journal of Bone and Joint Surgery. British Volume 2005;87(2):184-190.

24. Elhassan B. Technique of tendon transfers about the shoulder in patients with brachial plexus injury. JBJS Essential Surgical Techniques 
2012;2(4):19:12.

25. Kotwal PP, Mittal R, Malhotra R. Trapezius transfer for deltoid paralysis. Journal of Bone and Joint Surgery. British Volume 1998;80(1):114-116.

26. Mir-Bullo X, Hinarejos P, Mir-Batlle P, Busquets R, Carrera L, Navarro A. Trapezius transfer for shoulder paralysis. 6 patients with brachial plexus injuries followed for 1 year. Acta Orthopaedica Scandinavica 1998;69(1):69-72.

27. Rühmann O, Schmolke S, Bohnsack M, Carls J, Wirth CJ. Trapezius transfer in brachial plexus palsy. Correlation of the outcome with muscle power and operative technique. Journal of Bone and Joint Surgery. British Volume 2005;87(2):184-190.

28. Elhassan B, Bishop AT, Hartzler RU, Shin AY, Spinner RJ. Tendon transfer options about the shoulder in patients with brachial plexus injury. Journal of Bone and Joint Surgery: American Volume 2012;94(15):1391-1398.

29. Bertelli JA. Upper and lower trapezius muscle transfer to restore shoulder abduction and external rotation in longstanding upper type palsies of the brachial plexus in adults. Microsurgery 2011;34(4):263-267.

30. Steindler A. Reconstruction of the poliomyelitic upper extremity. Bulletin of the Hospital for Joint Diseases 1954;15(1):21-34.

31. Holtermann A, Roeleveld K, Mork PJ, et al. Selective activation of neuromuscular compartments within the human trapezius muscle. Journal of Electromyography and Kinesiology. 2009;19(5):896-902. 